XI.

\title{
Ueber den orbicularen Diorit von Corsica.
}

\author{
Von \\ A. Delesse.
}

(C. R. XXVII, 411.)

Der Feldspath des orbicularen Diorits von Corsica hat eine Dichtigkeit ron 2,737. Sie ist grōsser als dic des Anorthits, des Labradors und im Allgemeinen als die der Feldspathe, welche reich an Thonerde und an Kalk sind, jedoch geringer als die des Feldspaths aus dem Porphyr von Ternuay, welche ungefahr 2,77 beträgt. $\mathrm{Er}$ ist krystallisirt, und seine Form ist die, welche in den Felsarten die gewöhnliche ist, die der Feldspäthe des sechsten Systems; in dem Theile mit granitoidischer Structur hat er zuweilen die Form des Albits von Carlsbad, welche G. Rose beschrieben hat; meist erscheint er in sehr feinen Bläitchen, die sehr zart gestreift sind; diese Streifen sind meist strahlenförmig gegen einander gerichtet. Er wird sehr leicht von Chlorwasserstoffsāure aufgeschlossen; die Kieselsāure scheidet sich körnig aus.

Zur Analyse wăhlte ich sehr reine Blättchen von krystallinischer Structur aus, welche eine Kugelschale von 8 Centimeter Durchmesser bildeten. Mit kohlensaurem Natron und mit Flusssäure aufgeschlossen fand ich folgende Zusammensetzung:

\begin{tabular}{|c|c|c|c|c|c|c|}
\hline \multirow{2}{*}{ Kieselsäure } & \multicolumn{2}{|c|}{ Kohlens. Natron. } & \multirow[t]{2}{*}{ Flusss. } & \multirow[t]{2}{*}{ Mittel. } & \multicolumn{2}{|r|}{ Sauerstoff, } \\
\hline & 4856 & II. & & & & \\
\hline Thonerde & 35,01 & $\begin{array}{l}40,00 \\
34,90\end{array}$ & $\sqrt[34.10]{10}$ & $\begin{array}{l}40,02 \\
34,66\end{array}$ & & $\begin{array}{l}20,208 \\
16,186\end{array}$ \\
\hline Eisenoxydul & - & 0,66 & - & 0,66 & 0,146 & \\
\hline Kalkerde & - & 12,14 & 11,91 & 12,02 & 3,420 & \\
\hline Magnesia & - & - & 0,33 & 0,33 & 0,131 & \\
\hline Natron & - & - & 2,55 & 2,55 & 0,653 & 4,960 \\
\hline Ка & - & - & 1,05 & 1,05 & 0,180 & \\
\hline Wasser & - & $0, \mathbf{5 0}$ & - & 0,50 & 0,435 & \\
\hline & & & & $\overline{100,39}$ & & \\
\hline
\end{tabular}

Nach seinem Kieselsäuregehalt gehŏrt dieser Feldspath zu dem, welcher mit dem Namen Vosgit*) bezeichnet ist, doch un-

*) Vergl. Journ. XLV, 228 . 
terscheidet er sich von diesem ganz betrăchtlich. Er enthălt nămlich dreimal so viel Kalkerde, viel weniger Alkali und kaum etwas chemisch gebundenes Wasser; endlich ist seine Dichtigkeit etwa um 0,04 geringer.

Nimmt man das Sauerstoffyerhältniss der Basen, indem man die mit 1 Aequiv. Sauerstoff zusammen einmal, und das Wasser und das Eisen (als 0xydul) mit hinzurechnet, so findet man die Zahlen $=5: 3: 1$. Dieser Feldspath ist also als eine Varietăt des Vosgits zu betrachten, der zur allgemeinen Formel hat:

$$
\dot{\mathrm{R}}_{3} \ddot{\mathrm{Si}}_{4}+\ddot{\mathbf{R}}_{3} \ddot{\mathrm{S}}_{\text {. }}
$$

Diese Varielăt würde also eine Zwischenstufe sein, zwisctuen dem Feldspath des Porphyrs von Ternuay ${ }^{*}$ ), und dem Anorthit, dem sie sich durch den starken Kalk - und Thonerdegehalt und den yeringen an Alkali nähern würde.

Die Analyse der Hornblende hat gezeigt, dass sie eine sehr wenig verschiedene Zusammensetzung von der Hornblende des Syenits rom Ballon im Elsass hat.

Wenn man die Atom-Volumen des Vosgits und der Hornblende, welche den orbicularen Diorit von Corsica constituiren, berechnet, so findet man, dass sie unter einander in dem einfachen Verhältniss von 4:3 stehen. Uebrigens findet man dieses einfache Verhältniss nicht allein bei dem orbicularen Diorit, sondern bei allen Varietäten des Diorits, bei den Melaphyren, den Pyroxen-Porphyren, den Euphotiden, den Hyperiten u. s. w., und im Allgemeinen bei allen Felsarten mit 2 Elementen, die einen feurigen Ursprung besitzen, und als Basis einen Feldspath des sechsten Krystallsystems haben und ein Silicat des Eisens, der Magnesia des fünften Systems, wie des Amphibols, des Uralits, Pyroxens, Augits, Hypersthens oder des Diallags.

*) A. a. O. 219 (Ann. des Mines X1I, 237.) 